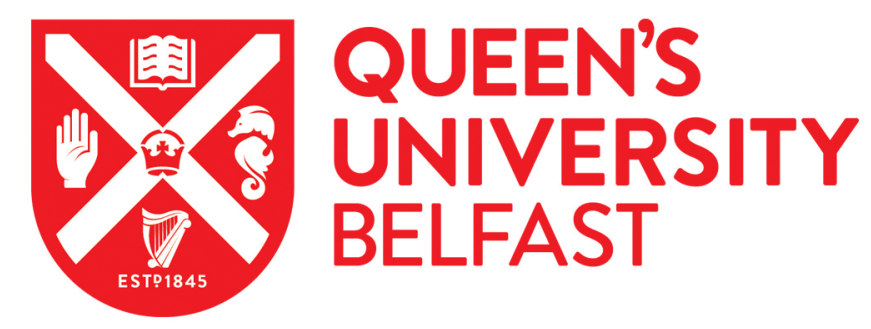

\title{
Insights into the factors associated with achieving the preference of home death in terminal cancer: A national population-based study
}

Bannon, F., Cairnduff, V., Fitzpatrick, D., Blaney, J., Gomes, B., Gavin, A., \& Donnelly, C. (2018). Insights into the factors associated with achieving the preference of home death in terminal cancer: A national populationbased study. Palliative and Supportive Care, 16(6), 749-755. https://doi.org/10.1017/S1478951517000876

Published in:

Palliative and Supportive Care

Document Version:

Peer reviewed version

Queen's University Belfast - Research Portal:

Link to publication record in Queen's University Belfast Research Portal

Publisher rights

(c) 2017 Cambridge University Press.

This work is made available online in accordance with the publisher's policies. Please refer to any applicable terms of use of the publisher.

\section{General rights}

Copyright for the publications made accessible via the Queen's University Belfast Research Portal is retained by the author(s) and / or other copyright owners and it is a condition of accessing these publications that users recognise and abide by the legal requirements associated with these rights.

Take down policy

The Research Portal is Queen's institutional repository that provides access to Queen's research output. Every effort has been made to ensure that content in the Research Portal does not infringe any person's rights, or applicable UK laws. If you discover content in the Research Portal that you believe breaches copyright or violates any law, please contact openaccess@qub.ac.uk. 
Title

Insights into the factors associated with achieving the preference of home death in terminal cancer: a national population-based study.

\section{Authors}

Finian Bannon ${ }^{1^{*}}$, Victoria Cairnduff ${ }^{*}$, Deirdre Fitzpatrick ${ }^{2}$, Janine Blaney ${ }^{3}$, Barbara Gomes ${ }^{4,5}$, Anna Gavin $^{2 \alpha}$, Conan Donnelly ${ }^{2 \alpha}$

*joint first authors

a Joint last authors

1: Centre for Public Health, Queen's University Belfast, Institute of Clinical Sciences Building, Grosvenor Road, Belfast BT126BJ, UK 2: Northern Ireland Cancer Registry, Queen's University Belfast, Centre for Public Health, Mulhouse Building,Grosvenor Road, Belfast BT12 6BJ, UK 3: Belfast City Hospital, Physiotherapy Department, Cancer Centre, Lisburn Road, Belfast BT9 7AB 4: University of Coimbra, Faculty of Medicine, Azinhaga de Santa Comba, Unidade 1 do Polo III, 3000548 Coimbra, Portugal. 5: King's College London, Cicely Saunders Institute, Dept. of Palliative Care, Policy \& Rehabilitation, Bessemer Road, London SE5 9RJ, United Kingdom

Corresponding Author: Finian Bannon Email: f.j.bannon@qub.ac.uk Tel: +44(0) 2890976292

Postal Address:Centre for Public Health, Queen's University Belfast, Centre for Public Health, Institute of Clinical Sciences Building, Grosvenor Road, Belfast BT12 6BJ, UK

Short Title:Factors associated with dying at home with cancer

List of Manuscript content:Number of Manuscript pages $=12$

Number of tables $=2$

Number of supplementary tables $=1$ 
Titlelnsights into the factors associated with achieving the preference of home death in terminal cancer: a national population-based study.

\section{Abstract}

Objectives: Most terminally-ill cancer patients prefer to die at home, yet only a minority achieve this. To investigate factors associated with cancer patients achieving their preference to die at home.

Methods: This study took the form of a mortality follow back, population-based, observational survey of relatives of deceased cancer patients in Northern Ireland. Individuals who registered the death of a friend or relative (aged $\geq 18 \mathrm{yrs}$ ) between 1/Dec/2011 and 31/May/2012, where the primary cause of death was cancer (ICD10: C00-D48) were invited to take part. Preferred and actual place of death,and patient, service and clinical data were collected using the Qualycare postal questionnaire. Multivariable logistic regression was used to investigate factors associated with achieving home death when this was preferred.

Results: 467 informants out of 1,493 invited completed the survey, 362 (77.5\%) expressed a preference of dying at home and spent time at home in their final three months were included in analysis. Of these, $53.4 \%$ achieved their preference for a home death. Factors positively associated with achieving home death were living in an affluent area, receipt of the good satisfactory district nurse care, discussing place of death with health professionals, and carer's preference for a home death. Being aged $>80$, Presbyterian religion, and being unconscious most of the time in their final week, were negatively associated with a home death.

Significance of Results: Communication, care satisfaction and carer preferences were all associated with home death. The findings will help inform the design of future interventions aimed at increasing the proportion of patients achieving preferred place of death at home, for example, by targeting interventions towards older patients and those from the most deprived communities.

\section{Keywords}

Bereavement, Communication, Home care services, Cancer, Palliative care 


\section{Introduction}

The End of Life (EOL) Care Strategy published by the Department of Health, London, (2008)highlights that one feature of good EOL care is enabling patients to die in their place of preference. For the majority of cancer patients,' this preferred place of death is home (Higginson \& Sen-Gupta, 2000; Becarro et al., 2006; Brazil et al., 2005; Gomes et al. 2013). However, in Northern Ireland (NI), only $34 \%$ of cancer patients achieve this (Blaney\& Gavin, 2011), in England 24.5\% (Gao et al., 2013), in contrast to $45.4 \%$ in the Netherlands (Cohen et al., 2010). A systematic review identified patient factors such as longer disease duration, solid tumour diagnosis, low functional status, expression of preference for a home death by patient or carer, rural status, married, living with relatives, and family support, white ethnic status, good social conditions as all positively associated with dying at home (Gomes et al., 2006). Compared to those who die in hospital there is evidence of better psychological and social wellbeing among cancer patients who died at home (Higginson, et al.,2013) while a recent study also reported better outcomes for grief and peace for those who died at home (Gomes et al., 2015).

The likelihood of achieving one's preference to die at home is complex and far from being understood as few studies investigate many factors at the same time. The aim here was to apply a multivariate approach that can estimate the relative strengths of association of several factors on achieving a home death and identify possible causal factors that could form the basis for potential interventions to increase terminally-ill cancer patients' likelihood of achieving a preferred home death.

\section{Methods}

\section{Survey}

A population-based survey of bereaved carers of adult cancer patients (aged 18 and over), who died between December 2011 and May 2012, was carried out in NI using death registration data. The Demography \& Methodology Branch of the Northern Ireland Statistics \& Research Agency administered the survey confidentially on behalf of the study team. Those individuals who had registered the death of a person who died of cancer (defined by ICD10 codes C00-D48) in the previous 4-6 months were invited to participate in the survey. The questionnaire, which focused on the patient's final three months of life, considered the type and quality of care the patients received 
(including care provided by informal carers, other family and friends), patient's health-related quality of life, palliative outcomes in the last week, the carer's perspective on care received and bereavement. The survey methodology was based on the Qualycare survey undertaken in London in 2009-10 (Gomes et al., 2010; Gomes et al. 2015), and the following tools, with adaptations, were included: Client Service Receipt Inventory (CSRI) (McCrone, 2009), Palliative Outcome Scale (POS) (Hearn \&Higginson, 1999),EuroQoL EQ-5D (Xia et al., 2005).

\section{Research question and study population}

The study explored potential independent variables associated with a patient who was receiving care at home achieving their preference to die at home. The patient inclusion criteria were 1) expressed a preference to die at home, 2) had spent some time at home in their last three months of life. The binary outcome variable was 'died at home' $(0 / 1)$. The potential independent variables were either drawn directly, or derived from one or more variables, from the questionnaire; as the study tested clearly-defined measures, only components of the scoring tools were used. The variables were classified into the following domains:

1. patient's demographics (sex, age, marital status, deprivation, religion),

2. patient's mental well-being,

3. patient's physical well-being,

4. patient's symptom severity,

5. how well the patient was informed about their treatment and place of death,

6. [perceived] quality of non-medical care provided at home,

7. quality of medical care provided at home,

8. quality of medical care provided outside the home,

9. carer factors (e.g. their relationship to the patient, their preferred place of death).

The independent variables' responses were simplified into binary variables (yes or no). All independent variables examined are listed in Supplementary Table I. A 'not-applicable' category was applied where appropriate. 


\section{Statistical analysis}

The outcome variable 'died at home' was related to the independent variables using logistic regression. To address non-response bias, each record in the analysis was weighted by its inverse probability of participation in the study after invitation; this probability was estimated by relating, through logistic regression, the patient's participation (0/1) to their sex, age, socio-economic deprivation, and place of death.

The reference level of independent variables was set in such a way to output the odds-ratio association of interest, e.g. yes: no; a nuisance parameter was used for the category 'not-applicable' or 'unknown' to remove these patients' influence from the association of interest. The model independent variables consisted of a base set of the demographic variables (domain 1 , Supplementary Table I) to which was added, singly, the variables across domains 2-9 (Supplementary Table I). The retained variables (with a coefficient significant at $<0.05$ ) formed, together with the domain-1 variables, an updated base set which was subject to a further round of single addition of variables through domains 2-9. The final list of variables for inclusion in the model is reported in Table II. Pairs of these variables were selected, considering effect sizes or a priori hypotheses, and tested for interaction along with the base set. Multivariate imputation (MI), using chained equations, was employed to handle missing values, when fitting the final model. Thevariables in the base set (Table II), which include the demographic variables, were used as the predictor equations for $\mathrm{Ml}$, and 10 sets of imputed data sets were combined to estimate effects and their standard errors. The analysis was carried out using Stata version 12.

\section{Results}

Of the 1,493 carers invited to participate in the study, $467(31.3 \%)$ responded. The percentage of patients aged 60-69 was lower in the response-group than the non-response group $(20.1 \%$ vs $41.0 \%$ $\mathrm{P}<0.001$, Table I). Among the response-group, a greater proportion of patients was 1) from the 'mostdeprived'socio-economic quintile $(17.3 \%$ vs $8.1 \%, \mathrm{P}<0.05)$, and 2$)$ died at home $(38.1 \%$ vs $32.7 \%, P<0.05$ ), than the non-response group. There was no difference in patient sex breakdown between response and non-response groups $(\mathrm{P}=0.80)$ (Table II). 
Place of death preference of the 467 patients was distributed as follows: home 349 (74.7\%), hospice 28 , hospital 16 , nursing home 8 , elsewhere 1 , no preference 23 , carer did not know 42 . Of those who preferred to die at home, 326 patients $(69.8 \%$ of 467$)$ spent some time at home and were included in the study. Of these, $53.4 \%$ achieved their preference for a home death. $99.0 \%$ of the patients' carers were relatives.

The final model, resulting from the forward-selection approach, is presented in Table II. The odds ratios derived from the multivariate analysis were sufficiently different from the univariate analysis to justify the former (particularly for deprivation). Factors that were positively associated with a patient's achieving their preference to die at home were living in an affluent area (least deprived: most deprived odds ratio [OR] $4.095 \%$ Confidence Interval [Cl] 1.4-11.8), receiving the satisfactory care at home from a district nurse (yes: no OR 6.1 [95\% Cl 2.5-15.2]), discussing with a health-care professional their place of death (yes: no OR 4.7 [95\% Cl 1.9-11.5]), and the carer's preference for place of death (home: elsewhere OR 17.7 [95\% Cl 5.3-59.3]). Factors inversely associated with achieving one's desire to die at home were age (over 80 years: under 70 OR 0.5 (95\% $\mathrm{Cl} 0.2-1.0)$, being unconscious most of the time in the last week (yes: no OR $0.1[95 \% \mathrm{Cl} 0.0-0.4]$ ), and Presbyterian religion (Presbyterian: Catholic OR 0.30 [95\% Cl 0.11-0.87]).

In the final model, McFadden's coefficient of determination $\left(R^{2}\right)$ (McFadden, 1974) for logistic regression was $46 \%$ and Tjur's (Tjur, 2009) R2 was 50\%. The Hosmer-Lemeshow goodness of fit test had a P-value of $\geq 0.25$ when the number of groups employed varied from $4-12$. The likelihood-ratio test's P-value was $>0.05$ when testing for interactions in the model.

\section{Discussion}

This is one of very few national population-based studies exploring patient, service and clinical factors associated with achieving preferred place of death at home for terminally-ill cancer patients (Weitzen et al., 2003 and Cohen et al., 2010). Younger patients and those from more affluent areas had a greaterlikelihood of dying at home, as did those patients whose carer's preference was for a homedeath. Discussion with a health professional about place of death, and good satisfaction with district nurse services increased the likelihood of achieving a home death.It is important to note that a greater 
proportion of patients in the response group were from the 'most deprived' socio-economic quintile than the non-response group. This is in contrast to findings observed in a previous mortality followback study of a similar design (Gomes et al, 2015) which observed a quarter (25.3\%) of respondents from the least deprived quintile and may have an impact the interpretation and representativeness of the findings.

It was encouraging that overall care was described as 'good or excellent' for the majority of patients across the different care settings (Supplementary Table I) suggesting a high standard of end of life care in a UK region. However, further qualitative work should be undertaken to investigate reported causes of dissatisfaction with care with a view to identifying improvements needed in palliative and end of life cancer care.

There was little evidence of an association between satisfaction with care and achieving a home death. However, those who felt they did not get the district nurse help they needed had significantly lower odds of achieving a home death. This perhaps reflected the extensive duties that district nurses perform spanning medical, hospice, and social support and is consistent with the conclusions from a review of factors associated with the congruence between preferred and actual death (Bell et al, 2010). While it is also possible that those dissatisfied with district nursing care had care needs that were more difficult to manage in a home setting, this was not apparent from the data collected in this study.

The importance of specific communication in achieving preferred place of death is evidenced with the strong, independent association between 'discussion of place of death with a health professional' and achieving a home death. As other direct patient-care factors were not so associated, it is likely that communication is more than a proxy for patient care. This may have been mediated both through patients and carers aligning preferences with care needs as well as a health care response to meet the preferences of patients and their carers (Bell et al. 2010). These findings reinforce the importance of clinician discussion about place of death reported in previous studies. This information should be recorded in the patient's clinical record to allow routine audit and monitoring. This has previously been highlighted as a component of best practice in community palliative care in NICE Guidance on end of 
life care(NICE, 2004) and has been reported in several research studies (Parker et al.,2007; Clayton et al., 2005). The extent to which this is applied is unclear.

In addition to communication, the role of family and carer support has been highlighted as very important in achieving preferred place of death. In particular, the carer's preference for place of patient's death three months prior to diagnosis was strongly associated with achievement of preferred place of death. This is consistent with a previous Japanese study (Ishikawa et al., 2013) that reported family preference for place of death is a mediator between patient preference and actual place of death and reflects the important role of carer support in end of life care in a home setting.

Family support may also explain the lower odds of Presbyterians achieving a home death compared to Church of Ireland, and Catholic denominations. Previous studies have reported smaller family size among Presbyterians compared to Catholics and other denominations (Compton et al., 1985). This is supported by the fact that Catholic respondents in this study were more likely to report family members looked after the patient (57\%) than Presbyterian (38\%) and Church of Ireland (30\%) respondents $(p<0.01)$. However, other cultural and social factors may also have a role in explaining this relationship. Future studies ought to include religion and ethnicity as demographic characteristics that may influence achievement of preferred place of death.

Despite the wide array of data collected on care and quality of life, the underlying drivers of the association between achieving a home death and demographic characteristics, such as younger age and living in more affluent areas, remain unclear. Though it is likely that these associations were mediated through social support, advocacy and communication, it is also possible that the pattern is explained by a greater burden of co-morbid disease in these populations, which may be manifested in more complex care needs of the patient, as well as limitations on carer capabilities.

\section{Strengths and weaknesses}

Few population-based studies have been undertaken to report end of life care experiences of cancer patients and little is understood about their care needs and satisfaction with care. The overall response rate was $31 \%$, while a low response rate was expected, given the sensitive subject matter 
and the target population surveyed, such response rates leave room for bias (Calanzani et al., 2016; Gomes et al. 2013). Comparing profiles of respondents to non-respondents, a greater proportion of non-responses were in the patient age-group 60-69, perhaps reflecting more spouse-carers who found participation difficult. In addition, responses were higher in patients living in lower socioeconomic areas. Inverse weighting by response probability was applied to compensate for observed profile differences. In addition, multivariate analysis and multiple imputation of missing values were used to reduce bias in estimation of population effect sizes. The multivariable modelling approach succeeded in isolating a small number of variables with significant associations.

Another important issue for consideration was the fact that patient's preference of death was not canvassed directly, and therefore its measurement is open to misclassification. However, $19 \%$ of care-givers did not concur with the patient's preference for a home death which broadly agrees, if not higher, with other studies (Bell et al., 2010; Gomes et al., 2015), and suggests, at least, that carers were discriminating theirs and the patient's preference. Even so, as patient preferences are shaped by a complex of issues (Tang, 2003) each of which may change during their illness, future studies may consider a prospective assessment of patient's preference at variable time points.

\section{Conclusions}

Several factors have been identified as associated with achieving preferred place of death at home. Interventions must target groups at high risk of not achieving preferences including the oldest patients and those from more deprived communities. It is evident that the rapidly changing healthand carerequirements in the last weeks of life mean that these preferences may change and may not always be achieved, however, for many, undesirable hospital deaths can be avoided with clear communication about preferences involving patients, carers and healthcare workers. Achievement ofhome death has the potential to improve the psychological aspects of dying for patients and their families. 


\section{Acknowledgements}

The authors thank Professor Irene Higginson and her research team at the Cicely Saunders Institute for the use of the instruments from the Qualycare study (funded by Cicely Saunders International). This study was funded by Cancer Focus NI and was carried out by the N. Ireland Cancer Registry which is funded by the Public Health Agency NI. We also thank the Northern Ireland Statistics and Research Agency for their facilitation of the survey methodology. Ethical approval was granted by Office of Research Ethics Committees Northern Ireland. 


\section{References}

Beccaro M, Costantini M, Giorgi RP, Miccinesi G, Grimaldi M, Bruzzi P, et al. (2006) Actual and preferred place of death of cancer patients. Results from the Italian survey of the dying of cancer (ISDOC).Journal of Epidemiology \& Community Health 60: 412-6.

Bell CL, Somogyi-Zalud E, Masaki KH (2010) Factors associated with congruence between preferred and actual place of death. Journal of Pain Symptom Management. 39: 591-604.

Blaney, J \& Gavin, AT ( 2011) Why do cancer patients die in acute hospitals. [Accessed at http://www.qub.ac.uk/research-centres/nicr September 2014]

Brazil K, Howell D, Bedard M, Krueger P, Heidebrecht C. (2005) Preferences for place of care and place of death among informal caregivers of the terminally ill. Palliative Medicine 19: 492-9.

Calanzani, N., Higginson, I.J., Koffman, J. and Gomes, B. (2016) Factors Associated with Participation, Active Refusals and Reasons for Not Taking Part in a Mortality Followback Survey Evaluating End-of-Life Care. PloS one, 11:1:e0146134.

Cohen J, Houttekier D, Onwuteaka-Philipsen B, Miccinesi G, Addington- Hall J, Kaasa S, et al.(2010) Which patients with cancer die at home? A study of six European countries using death certificate data.Journal of Clinical Oncology 28: 2267-73.

Clayton J, Butow P, Arnold RM, Tattersall MH. (2005) Discussing end-of-life issues with terminally ill cancer patients and their carers: a qualitative study. Support Care Cancer 13:8:589e599.

Compton, P.A., Coward, J. and Wilson-Davis, K. (1985) Family size and religious denomination in Northern Ireland.Journal of biosocial science, 17:02:137-145. 
Department of Health (2008) End of Life Care Strategy - promoting high quality care for all adults atthe end of life. [Accessed at https://www.gov.uk/government/publications September 2014]

Gao W, Ho YK, Verne J, Glickman M, Higginson IJ. (2013) Changing patterns in place of cancer death in England: a population-based study. PLoS Medicine 10:e1001410.

Gomes B, Higginson IJ (2006) Factors influencing death at home in terminally ill patients with cancer: systematic review. British Medical Journal 332: 515-21.

Gomes B, McCrone P, Hall S, Koffman J, Higginson IJ (2010) Variations in the quality and costs of end-of-life care, preferences and palliative outcomes for cancer patients by place of death: the QUALYCARE study.BioMed Centre Cancer 10:400.

Gomes B, Calanzani N, Gysels M, Hall S, Higginson IJ (2013) Heterogeneity and changes in preferences for dying at home: a systematic review.BMC Palliative care 15:12-7.

Gomes, B., Calanzani, N., Koffman, J. and Higginson, I.J. (2015) Is dying in hospital better than home in incurable cancer and what factors influence this? A population-based study.BMC medicine 13:1:1.

Hearn J, Higginson IJ (1999) Development and validation of a core outcome measure for palliative care: the palliative care outcome scale. Palliative Care Core Audit Project Advisory Group. Quality inHealth Care 8:219-27.

Higginson IJ, Sen-Gupta GJA (2000) Place of care in advanced cancer: a qualitative systematic literature review of patient preferences. Journal of Palliative Medicine 3: 287-300

Higginson, I.J., Sarmento, V.P., Calanzani, N., Benalia, H. and Gomes, B.(2013) Dying at home-is it better: a narrative appraisal of the state of the science. Palliative medicine, 27:10: 918-924. 
Ishikawa Y1, Fukui S, Saito T, Fujita J, Watanabe M, Yoshiuchi K (2013) Family preference for place of death mediates the relationship between patient preference and actual place of death: a nationwide retrospective cross-sectional study. PLoS One 8: e56848.

McCrone P ( 2009) Capturing the costs of end-of-life care: comparisons of multiple sclerosis, Parkinson's disease, and dementia. Journal of Pain \& Symptom Management 38: 62-7.

McFadden, D. (1974) Conditional logit analysis of qualitative choice behavior. In Frontiers in Econometrics.Zarembka, P (ed) pp. 105-142 Academic Press.

National Institute of Clinical Excellence (2004) Improving Supportive and Palliative Care for Adults with Cancer. Accessed at https://www.nice.org.uk/guidance/csg4/evidence

Parker, S.M., Clayton, J.M., Hancock, K., Walder, S., Butow, P.N., Carrick, S., Currow, D., Ghersi, D., Glare, P., Hagerty, R. and Tattersall, M.H. (2007) A systematic review of prognostic/end-of-life communication with adults in the advanced stages of a life-limiting illness: patient/caregiver preferences for the content, style, and timing of information. Journal of pain and symptommanagement, 34:1:81-93.

Tang ST (2003) When death is imminent: where terminally ill patients with cancer prefer to die and why. Cancer Nursing 26: 245-51.

Tjur T. (2009) Coefficients of determination in logistic regression models-A new proposal: The coefficient of discrimination. The American Statistician 63: 366-372.

Weitzen, S, Teno, JM, Fennell, M, Mor, V (2003) Factors associated with site of death: a national study if where people die. Medical Care.41:2:323-35. 
Xia W, Hwang SS, Chang VT, Osenenko P, Alejandro Y, Yan H, et al. (2005) Validity, reliability and responsiveness of Euroqol (EQ5D) in patients (Pts) receiving palliative care (PC). Journal of ClinicalOncology. 22:S16:8082.

Table I: Comparison between respondents and non-respondents' distribution of place of death anddemographic characteristics

\begin{tabular}{|c|c|c|c|c|}
\hline Variable-categories & $\begin{array}{l}\text { Non- } \\
\text { respondents } \\
(\mathrm{n}=1026)\end{array}$ & $\begin{array}{l}\text { Respondents } \\
(\mathrm{n}=467)\end{array}$ & $\begin{array}{l}\text { All persons } \\
(n=1493)\end{array}$ & $P$-value \\
\hline \multicolumn{5}{|l|}{ Place of death: } \\
\hline NHS Hospital & $449(43.8 \%)$ & $204(43.7 \%)$ & $653(43.7 \%)$ & \multirow{4}{*}{0.064} \\
\hline Home & $335(32.7 \%)$ & $178(38.1 \%)$ & $513(34.4 \%)$ & \\
\hline Hospice & $130(12.7 \%)$ & $43(9.2 \%)$ & $173(11.6 \%)$ & \\
\hline Nursing Home & $112(10.9 \%)$ & $42(9.0 \%)$ & $154(10.3 \%)$ & \\
\hline \multicolumn{5}{|l|}{ Age groups: } \\
\hline $0-59$ & $160(15.6 \%)$ & $62(13.3 \%)$ & $222(14.9 \%)$ & \multirow{4}{*}{$<0.001$} \\
\hline $60-69$ & $421(41.0 \%)$ & $94(20.1 \%)$ & $515(34.5 \%)$ & \\
\hline $70-79$ & $275(26.8 \%)$ & $154(33.0 \%)$ & $429(28.7 \%)$ & \\
\hline $80+$ & $170(16.6 \%)$ & $157(33.6 \%)$ & $327(21.9 \%)$ & \\
\hline \multicolumn{5}{|l|}{ Patient sex: } \\
\hline Male & $544(53.0 \%)$ & $251(53.7 \%)$ & $795(53.2 \%)$ & \multirow[b]{2}{*}{0.80} \\
\hline Female & $482(47.0 \%)$ & $216(46.3 \%)$ & $698(46.8 \%)$ & \\
\hline \multicolumn{5}{|c|}{ Socio-economic deprivation } \\
\hline Most Deprived & $83(8.1 \%)$ & $81(17.3 \%)$ & $164(11.0 \%)$ & \multirow{5}{*}{$<0.001$} \\
\hline 2 & $144(14.0 \%)$ & $104(22.3 \%)$ & $248(16.6 \%)$ & \\
\hline 3 & $373(36.4 \%)$ & $114(24.4 \%)$ & 487 (32.6\%) & \\
\hline 4 & $265(25.8 \%)$ & $80(17.1 \%)$ & $345(23.1 \%)$ & \\
\hline Most affluent & $161(15.7 \%)$ & $88(18.8 \%)$ & $249(16.7 \%)$ & \\
\hline \multicolumn{5}{|c|}{$\begin{array}{l}{ }^{*} \text { P-value: the probability that the distributions of respondents and non-respondents are the same } \\
\text { (i.e. the null hypothesis) given the Chi-square statistic assuming independence, conventionally the } \\
\text { null hypothesis is rejected in the P-value }<0.05 \text {. }\end{array}$} \\
\hline
\end{tabular}


Table II: The association between a patient's desire to die at home and various explanatory factors explored through both univariate andmultivariable analysis

\begin{tabular}{|c|c|c|c|c|c|c|c|c|}
\hline \multirow[t]{2}{*}{ Factors } & \multirow{2}{*}{$\begin{array}{c}\text { Categories } \\
\text { Overall }\end{array}$} & \multicolumn{2}{|c|}{$\begin{array}{l}\text { Achieved preference to die at home } \\
\text { [observed] }(n=362)\end{array}$} & \multicolumn{2}{|c|}{ Univariate analysis } & \multicolumn{3}{|c|}{ Multivariate analysis $^{1}$} \\
\hline & & $\begin{array}{c}\mathrm{N} \\
(42.0 \%=152 / 362)\end{array}$ & $\begin{array}{c}\mathrm{Y} \\
(58.0 \%=174 / 362)\end{array}$ & Odds ratio & $\begin{array}{c}\text { P- } \\
\text { value }\end{array}$ & Odds ratio & $\begin{array}{c}\mathrm{P}- \\
\text { value }\end{array}$ & Predicted \\
\hline \multirow[t]{2}{*}{ Sex } & Male (ref) & $52.2 \%(96 / 184)$ & $47.8 \%(88 / 184)$ & 1 & - & 1 & - & $49.7 \%(42.8 \%, 56.6 \%)$ \\
\hline & Female & $39.4 \%(56 / 142)$ & $60.6 \%(86 / 142)$ & $1.7(1.1,2.6)$ & 0.023 & $1.6(0.7,3.4)$ & 0.247 & $56.1 \%(48.7 \%, 63.4 \%)$ \\
\hline \multirow[t]{3}{*}{ Age Category } & $0-69$ (ref) & $42.5 \%(45 / 106)$ & $57.5 \%(61 / 106)$ & 1 & - & 1 & - & $53.2 \%(45.5 \%, 61.0 \%)$ \\
\hline & $70-79$ & $42.6 \%(46 / 108)$ & $57.4 \%(62 / 108)$ & $1.0(0.6,1.7)$ & 0.984 & $1.8(0.7,4.2)$ & 0.196 & $60.9 \%(53.1 \%, 68.8 \%)$ \\
\hline & $80+$ & $54.5 \%(61 / 112)$ & $45.5 \%(51 / 112)$ & $0.6(0.4,1.1)$ & 0.077 & $0.5(0.2,1.0)$ & 0.049 & $41.9 \%(33.8 \%, 50.1 \%)$ \\
\hline \multirow[t]{5}{*}{ Religion } & Catholic & $37.8 \%(48 / 127)$ & $62.2 \%(79 / 127)$ & $2.2(1.3,3.8)$ & 0.005 & $3.3(1.2,9.4)$ & 0.026 & $58.3 \%(50.2 \%, 66.4 \%)$ \\
\hline & Presbyterian (ref) & $57.3 \%(51 / 89)$ & $42.7 \%(38 / 89)$ & 1 & - & 1 & - & $41.7 \%(31.6 \%, 51.8 \%)$ \\
\hline & Church of Ireland & $45.2 \%(28 / 62)$ & $54.8 \%(34 / 62)$ & $1.6(0.8,3.1)$ & 0.143 & $2.8(0.9,9.1)$ & 0.088 & $56.1 \%(45.3 \%, 67.0 \%)$ \\
\hline & Other & $52.4 \%(22 / 42)$ & $47.6 \%(20 / 42)$ & $1.2(0.6,2.5)$ & 0.597 & $2.0(0.5,7.4)$ & 0.293 & $51.6 \%(36.6 \%, 66.6 \%)$ \\
\hline & $M$ & $3 / 6$ & $3 / 6$ & - & - & - & - & \\
\hline \multirow[t]{6}{*}{ Deprivation } & Most Deprived & $55.2 \%(32 / 58)$ & $44.8 \%(26 / 58)$ & 1 & - & 1 & - & $42.4 \%(31.9 \%, 52.8 \%)$ \\
\hline & 2 & $43.8 \%(32 / 73)$ & $56.2 \%(41 / 73)$ & $1.6(0.8,3.2)$ & 0.198 & $1.3(0.5,3.5)$ & 0.624 & $46.0 \%(35.8 \%, 56.1 \%)$ \\
\hline & 3 & $39.5 \%(30 / 76)$ & $60.5 \%(46 / 76)$ & $1.9(0.9,3.8)$ & 0.072 & $2.6(1.0,7.3)$ & 0.06 & $56.1 \%(47.0 \%, 65.3 \%)$ \\
\hline & 4 & $48.2 \%(27 / 56)$ & $51.8 \%(29 / 56)$ & $1.3(0.6,2.8)$ & 0.458 & $2.1(0.6,6.6)$ & 0.225 & $52.7 \%(40.9 \%, 64.6 \%)$ \\
\hline & Most Affluent & $49.2 \%(30 / 61)$ & $50.8 \%(31 / 61)$ & $1.3(0.6,2.6)$ & 0.513 & $4.0(1.4,11.8)$ & 0.011 & $61.8 \%(52.1 \%, 71.6 \%$ \\
\hline & $M$ & $1 / 2$ & $1 / 2$ & - & - & - & - & \\
\hline \multirow{3}{*}{$\begin{array}{l}\text { Unconscious in the } \\
\text { last week }\end{array}$} & $\mathrm{Y}$ & $60.7 \%(17 / 28)$ & $39.3 \%(11 / 28)$ & $0.5(0.2,1.2)$ & 0.108 & $0.1(0.0,0.4)$ & 0.002 & $27.3 \%(6.3 \%, 48.3 \%)$ \\
\hline & $N($ ref) & $44.6 \%(129 / 289)$ & $55.4 \%(160 / 289)$ & 1 & - & 1 & - & $55.3 \%(50.5 \%, 60.2 \%)$ \\
\hline & $M$ & $6 / 9$ & $3 / 9$ & - & - & - & - & \\
\hline \multirow{4}{*}{$\begin{array}{l}\text { Got the district nurse } \\
\text { help needed at } \\
\text { home }\end{array}$} & $\bar{Y}$ & $32.2 \%(69 / 214)$ & $67.8 \%(145 / 214)$ & $7.0(3.5,14.2)$ & $<0.001$ & $6.1(2.5,15.2$ & $<0.001$ & $64.2 \%(58.3 \%, 70.0 \%)$ \\
\hline & Otherwise (ref) & $76.9 \%(40 / 52)$ & $23.1 \%(12 / 52)$ & 1 & - & 1 & - & $34.9 \%(21.5 \%, 48.4 \%)$ \\
\hline & Not applicable $^{2}$ & $75.5 \%(40 / 53)$ & $24.5 \%(13 / 53)$ & $1.1(0.4,2.7)$ & 0.518 & $0.4(0.1,1.3)$ & 0.123 & $20.2 \%(7.7 \%, 32.8 \%)$ \\
\hline & $M$ & $3 / 7$ & $4 / 7$ & - & - & - & - & \\
\hline \multirow{3}{*}{$\begin{array}{c}\text { Place of death } \\
\text { discussed with HCP }\end{array}$} & $\mathrm{Y}$ & $27.2 \%(40 / 147)$ & $72.8 \%(107 / 147)$ & $4.8(2.8,8.3)$ & $<0.001$ & $4.7(1.9,11.5)$ & 0.001 & $62.4 \%(55.2 \%, 69.6 \%)$ \\
\hline & $N$ (ref) & $64.4 \%(67 / 104)$ & $35.6 \%(37 / 104)$ & 1 & - & 1 & - & $39.3 \%(29.9 \%, 48.6 \%)$ \\
\hline & $M$ & $45 / 75$ & $30 / 75$ & - & - & - & - & \\
\hline \multirow[t]{4}{*}{$\begin{array}{l}\text { Carer's preferred } \\
\text { place of death }\end{array}$} & At home & $37.2 \%(99 / 266)$ & $62.8 \%(167 / 266)$ & $12.1(4.6,32.0)$ & $<0.001$ & $\begin{array}{c}17.7(5.3 \\
59.3) \\
\end{array}$ & $<0.001$ & $59.2 \%(53.6 \%, 64.8 \%)$ \\
\hline & Elsewhere (ref) & $87.8 \%(36 / 41)$ & $12.2 \%(5 / 41)$ & 1 & - & 1 & - & $17.0 \%(4.6 \%, 29.4 \%)$ \\
\hline & No preference $^{3}$ & $88.9 \%(16 / 18)$ & $11.1 \%(2 / 18)$ & $0.9(0.2,5.1)$ & 0.906 & $0.8(0.1,4.3)$ & 0.798 & $14.7 \%(2.0 \%, 27.4 \%)$ \\
\hline & $M$ & & & & & & - & \\
\hline
\end{tabular}

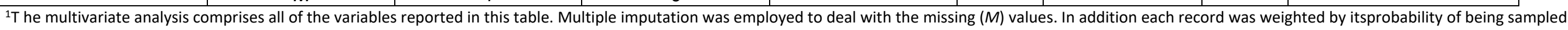
based on the variables in Table 1 for responders and non-responders. ${ }^{2}$ Seven patients did not want help, and help was not needed for the remainder ( $\mathrm{n}=40$ ). 
Supplementary Table I: List of variables taken directly, or derived, from the questionnaire and classified into domains, with each variable's categories and numbers in each of categories.

\begin{tabular}{|c|c|c|}
\hline $\begin{array}{l}\text { Variable } \\
\text { domain }\end{array}$ & Question variable & $\begin{array}{l}\text { Categories }(\mathrm{y}=\mathrm{yes}, \mathrm{n}=\mathrm{no}, \mathrm{na}=\mathrm{not}- \\
\text { applicable, } \mathrm{m}=\text { missing) }\end{array}$ \\
\hline \multirow{5}{*}{$\begin{array}{l}\text { Patient's } \\
\text { demographics } \\
(=1)\end{array}$} & Patient is married or with partner? & $\mathrm{y}=198, \mathrm{n}=123, \mathrm{~m}=5$ \\
\hline & Patient's religion & $\begin{array}{l}\text { Catholic }=127, \text { Presbyterian }=89, \\
\text { Church of Ireland }=62, \text { Other }=42, \\
m=6\end{array}$ \\
\hline & Sex of patient & male $=184$, female $=142$ \\
\hline & Age at death of patient & $\begin{array}{l}0-69=106 ; 70-79=108 ; 80+=112 \\
{[\text { mean 73.8] }}\end{array}$ \\
\hline & Patient's deprivation quintile & $\begin{array}{l}\text { Most Deprived[1] }=58,2=73,3=76 \text {, } \\
4=56, \text { Most affluent[5] }=61, m=2\end{array}$ \\
\hline \multirow{5}{*}{$\begin{array}{l}\text { Patient's } \\
\text { mental fitness } \\
(=2)\end{array}$} & Extreme anxiety/depression at three months before he/she died? & $\mathrm{y}=25, \mathrm{n}=292, \mathrm{~m}=9$ \\
\hline & Extreme anxiety/depression in the last week? & $\mathrm{y}=68, \mathrm{n}=231, \mathrm{~m}=27$ \\
\hline & Confused in the last week before death most of the time? & $\mathrm{y}=42, \mathrm{n}=278, \mathrm{~m}=6$ \\
\hline & Over the last week, was patient feeling anxious or worried about illness or treatment most of the time? & $\mathrm{y}=48, \mathrm{n}=272, \mathrm{~m}=6$ \\
\hline & Over the last week, did patient seem to be feeling depressed most of the time? & $y=46, n=265, m=15$ \\
\hline \multirow{5}{*}{$\begin{array}{l}\text { Patient's } \\
\text { physical fitness } \\
(=3)\end{array}$} & Extreme anxiety/depression at three months before he/she died? & $y=25, n=292, m=9$ \\
\hline & Extreme anxiety/depression in the last week? & $y=68, n=231, m=27$ \\
\hline & Confused in the last week before death most of the time? & $y=42, n=278, m=6$ \\
\hline & Over the last week, was patient feeling anxious or worried about illness or treatment most of the time? & $y=48, n=272, m=6$ \\
\hline & Over the last week, did patient seem to be feeling depressed most of the time? & $y=46, n=265, m=15$ \\
\hline \multirow{10}{*}{$\begin{array}{l}\text { Patient's } \\
\text { physical } \\
\text { fitness (=3) }\end{array}$} & Did the patient stay in a hospital intensive care unit? & $y=38, n=288$ \\
\hline & Did the patient stay in another hospital unit or ward? & $y=236, n=90$ \\
\hline & Did the patient visit A\&E? & $y=169, n=156, m=1$ \\
\hline & Did the patient use ambulance services? & $y=176, n=149, m=1$ \\
\hline & Confined to bed at three months before he/she died? & $y=23, n=289, m=14$ \\
\hline & Confined to bed in the last week? & $y=262, n=53, m=11$ \\
\hline & Unable to perform self care at three months before he/she died? & $y=61, n=250, m=15$ \\
\hline & Unable to perform self care in the last week? & $\mathrm{y}=279, \mathrm{n}=40, \mathrm{~m}=7$ \\
\hline & Unable to perform usual activities at three months before he/she died? & $y=115, n=197, m=14$ \\
\hline & Unable to perform usual activities in the last week? & $y=309, n=12, m=5$ \\
\hline $\begin{array}{l}\text { Variable } \\
\text { domain }\end{array}$ & Question variable & $\begin{array}{l}\text { Categories (y=yes, } n=n o, \text { na=not- } \\
\text { applicable, } m=\text { missing) }\end{array}$ \\
\hline \multirow{3}{*}{$\begin{array}{l}\text { Patient's } \\
\text { symptom } \\
\text { severity }(=4)\end{array}$} & Unconscious or in a coma during the last week before death most of the time? & $y=28, n=289, m=9$ \\
\hline & Over the last week, was the patient affected by pain despite medication most of the time? & $\mathrm{y}=90, \mathrm{n}=229, \mathrm{~m}=7$ \\
\hline & Over the last week, did other symptoms seem to affect how patient was feeling most of the time? & $y=78, n=241, m=7$ \\
\hline
\end{tabular}


Severe/overwhelming weakness or lack of energy in the last week despite medication

Severe/overwhelming shortness of breath in the last week despite medication

$\mathrm{y}=272, \mathrm{n}=43, \mathrm{~m}=11$

Severe/overwhelming nausea in the last week despite medication

Severe/overwhelming vomiting in the last week despite medication

Severe/overwhelming constipation in the last week despite medication

$\mathrm{y}=142, \mathrm{n}=176, \mathrm{~m}=8$

$\mathrm{y}=64, \mathrm{n}=246, \mathrm{~m}=16$

$\mathrm{y}=38, \mathrm{n}=263, \mathrm{~m}=25$

Severe/overwhelming diarrhoea in the last week despite medication

$\mathrm{y}=66, \mathrm{n}=238, \mathrm{~m}=22$

$\mathrm{y}=38, \mathrm{n}=260, \mathrm{~m}=28$

Severe/overwhelming drowsiness in the last week despite medication

$\mathrm{y}=152, \mathrm{n}=160, \mathrm{~m}=14$

Severe/overwhelming difficulty communicating in the last week despite medication

$\mathrm{y}=102, \mathrm{n}=208, \mathrm{~m}=16$

Extreme pain/discomfort at three months before he/she died

$\mathrm{y}=58, \mathrm{n}=258, \mathrm{~m}=10$

Extreme pain/discomfort in the last week

How well the

patient was

informed $(=5)$

Did GP in the home listen and discuss things fully with the patient or carer?

Did palliative specialists in the home listen and discuss things fully with the patient or carer?

$\mathrm{y}=164, \mathrm{n}=144, \mathrm{~m}=18$

$\mathrm{y}=239, \mathrm{n}=83, \mathrm{na}=2, \mathrm{~m}=2$

Did nurse in the home listen and discuss things fully with the patient or carer?

Did hospital doctors listen and discuss things fully with the patient or carer?

$\mathrm{y}=187, \mathrm{n}=25, \mathrm{na}=110, \mathrm{~m}=4$

$\mathrm{y}=209, \mathrm{n}=35, \mathrm{na}=75, \mathrm{~m}=7$

$\mathrm{y}=163, \mathrm{n}=87, \mathrm{na}=74, \mathrm{~m}=2$

Did hospital nurses listen and discuss things fully with the patient or carer?

$\mathrm{y}=152, \mathrm{n}=88, \mathrm{na}=84, \mathrm{~m}=2$

Did hospice doctors listen and discuss things fully with the patient or carer?

$\mathrm{y}=36, \mathrm{n}=9$, na=281

Did hospice nurses listen and discuss things fully with the patient or carer?

$\mathrm{y}=37, \mathrm{n}=8, \mathrm{na}=281$

In the care home, did nurses listen and discuss things fully with the patient or carer?

$y=14, n=5, n a=306, m=1$

In the care home, did the GPs listen and discuss things fully with the patient or carer?

In the care home, did the palliative specialist listen and discuss things fully with the patient or carer? $\quad \mathrm{y}=3, \mathrm{n}=2, \mathrm{na}=321$

In the care home, did the district nurses listen and discuss things fully with the patient or you?

During the final three months, did patient have a key contact person to rely on to get things done?

$\mathrm{y}=4, \mathrm{n}=1, \mathrm{na}=321$

$\mathrm{y}=234, \mathrm{n}=70, \mathrm{~m}=22$

$\mathrm{y}=278, \mathrm{n}=25, \mathrm{~m}=23$

Was patient aware of going to die because of illness?

$y=163, n=62, n a=48, m=53$

illness?

Over the last week, was full information given to patient and family?

Did the patient discuss their preferred place of death with any health professional?

$\mathrm{y}=223, \mathrm{n}=100, \mathrm{~m}=3$

$y=147, n=104, m=75$

\section{Question variable}

Categories (y=yes, $n=$ no, na=not-

applicable, $\mathrm{m}=$ missing)

Did the patient have any help from a paid home care worker in the patient's final three months?

$\mathrm{y}=76, \mathrm{n}=247, \mathrm{~m}=3$

Did more than two family or friends look after or help take care of the patient in the patient's final three

months?

nonmedica

care

provided at

home $(=6)$

three months?

Did family \& friends help the patient for more than 9 hours per week with household tasks in the patient's

final three months?

Was patient managing financially well in the last three months?

$y=152, n=162, m=12$

$y=174, n=141, m=11$

$\mathrm{y}=189, \mathrm{n}=119, \mathrm{~m}=18$

$\mathrm{y}=298, \mathrm{n}=26, \mathrm{~m}=2$

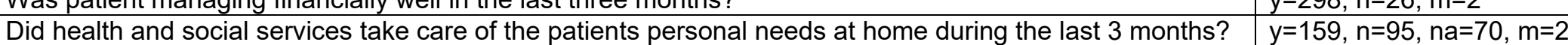


Quality of medical care provided at home (=7)

Quality of medical care provided outside the home (=8)

\section{Variable}

domain

Carer factors

(=9)
Did the patient get as much help as needed from the GP at home?

Was overall rating of care from the GP at home good to excellent?

Did the patient get as much help at home as needed from the team from hospice, palliative care, Marie Curie or Macmillan or other specialists?

Was overall rating of care from teams from hospice/palliative care visit at home good to excellent?

Did the patient get as much help as needed from the nurses?

Was overall rating of care from the district/community nurses at home good to excellent?

Was overall rating of care from all the services at home good to excellent?

Did hospital staff take care of the patients personal needs as well as they should have?

Did the patient get as much help and support as needed from the hospital doctors?

Was overall rating of care from the hospital doctors good to excellent?

Did the patient get as much help and support as needed from the hospital nurses?

Was overall rating of care from the hospital nurses good to excellent?

Was it very helpful was it to see the palliative care or Macmillan team at the hospital?

Was overall rating of care from the palliative care or Macmillan team good to excellent?

Did patient get as much help and support as needed from all the services at the hospital?

Was overall rating of care while from all the services at the hospital good to excellent?

Did patient get as much help and support as needed from all the services at the hospice?

Was overall rating of care from all the services at the hospice good to excellent?

Did patient get as much help and support as needed from all the services at the nursing/residential home?

Was overall rating of care from all the services at the nursing/residential home good to excellent?

\section{Question variable}

\section{Categories (y=yes, $n=$ no, na=not-}

applicable, $\mathrm{m}=$ missing)

Number of days respondent was off work before patient died

Relationship of respondent with patient

Was respondent aware the patient was going to die because of illness

Did the patient discuss his/her preference with the respondent, family members or friends?

$\mathrm{y}=205, \mathrm{n}=88, \mathrm{na}=31, \mathrm{~m}=2$

$\mathrm{y}=227, \mathrm{n}=67, \mathrm{na}=31, \mathrm{~m}=1$

$\mathrm{y}=170, \mathrm{n}=85, \mathrm{na}=64, \mathrm{~m}=7$

$\mathrm{y}=192, \mathrm{n}=64, \mathrm{na}=64, \mathrm{~m}=6$

$\mathrm{y}=214, \mathrm{n}=52, \mathrm{na}=53, \mathrm{~m}=7$

$y=221, n=41, n a=53, m=11$

$\mathrm{y}=210, \mathrm{n}=55, \mathrm{na}=56, \mathrm{~m}=5$

$y=174, n=46, n a=105, m=1$

$y=179, n=71, n a=74, m=2$

$y=193, n=56, n a=73, m=4$

$\mathrm{y}=157, \mathrm{n}=89, \mathrm{na}=77, \mathrm{~m}=3$

$\mathrm{y}=193, \mathrm{n}=54, \mathrm{na}=73, \mathrm{~m}=6$

$y=122, n=58, n a=145, m=1$

$\mathrm{y}=110, \mathrm{n}=69, \mathrm{na}=145, \mathrm{~m}=2$

$\mathrm{y}=163, \mathrm{n}=87, \mathrm{na}=73, \mathrm{~m}=3$

$\mathrm{y}=185, \mathrm{n}=64, \mathrm{na}=73, \mathrm{~m}=4$

$y=41, n=4, n a=281$

$y=43, n=2, n a=281$

$y=17, n=7, n a=301, m=1$

$y=20, n=4, n a=301, m=1$

Less than $16=62$, More than

$16=105$, na=145, $m=14$

Spouse/partner $=91$,

Son/daughter=176, Other

[relative, friend, neighbour] $=59$

$\mathrm{y}=282, \mathrm{n}=37, \mathrm{~m}=7$

Was home the place where the respondent would have preferred the patient to die 3 months before death $\mathrm{y}=228, \mathrm{n}=90, \mathrm{~m}=8$ 